\title{
EL TEMOR A UNA MUERTE APELMAZADA \\ Las epidemias de viruela en el Estado Soberano de Santander 1857 - 1886
}

Dayana Lucía Lizcano Herrera ${ }^{1}$

Universidad Santo Tomás - Bucaramanga

\section{Resumen}

Desde su aparición, en el periodo colonial, en el territorio que hoy conforma Colombia, la viruela fue una enfermedad que generó un fuerte impacto social y político, por la capacidad de diezmar drásticamente la población y provocar secuelas irreversibles en quienes lograban sobrevivir. No obstante, son exiguos los estudios históricos realizados sobre esta enfermedad y la respuesta de los actores encargados de contener su propagación y disminuir sus alcances. El presente artículo hace parte de un trabajo de investigación histórica para optar al título de Magíster, con el cual se buscó identificar la política de salubridad pública orientada a prevenir y controlar la viruela en el Estado Soberano de Santander entre 1857 y 1886 a través del análisis de la reglamentación dictada por el Gobierno Central y el Estado Soberano. La investigación permitió conocer las respuestas que los diferentes organismos y la población en general dieron a las epidemias de viruela, la apropiación de los métodos enfocados a la contención de la enfermedad y la resistencia a los mismos por parte de los diferentes sectores sociales.

\section{Palabras clave}

Epidemias, Viruela y Estado Soberano de Santander.

\section{FEAR TO A GOMPRESSED DEATH The epidemics of smallpox in the Sovereign State of Santander 1857-1886}

\section{Abstract}

From its appearance, in the colonial period, in the territory that today makes up Colombia, the smallpox was a disease that generated a strong social and political impact, for its capacity to decimate the population drastically and to bring about irreversible sequels in those who managed to survive. However, the historical studies carried out on this disease and the answer of the actors in charge of containing their propagation and to diminish their reaches are meager. The present article is part of a work of historical investigation for a Master's Degree, with which it was intended to identify the policy of public health oriented to prevent and to control the smallpox in the Sovereign State of Santander between 1857 and 1886 through analysis of the regulation dictated by the Central Government and Sovereign State. The research allowed knowing the responses given by the different organisms and the population to the smallpox epidemics, the appropriation of the methods focused to the containment of the disease and the resistance to the same by the different social sectors.

\section{Kev Words}

Epidemics, Smallpox and Sovereign State of Santander.

\footnotetext{
1 Historiadora y Magíster en Historia de la Universidad Industrial de Santander, Docente del Departamento de Humanidades de la Universidad Santo Tomás Seccional Bucaramanga y de las Unidades Tecnológicas de Santander. Vinculado al Grupo de Investigaciones Históricas sobre el Estado-Nacional Colombiano, registrado en COLCIENCIAS en categoría B. mhuisdaliz@hotmail.com
} 


\section{Introducción}

La investigación histórica sobre las epidemias de viruela a partir del análisis de los indicadores demográficos, tasas de mortalidad y políticas públicas para contenerla, ha demostrado su impacto social en términos del amplio cúmulo de víctimas fatales que cobró alrededor del mundo o en función de una historia de las mentalidades dado el carácter siniestro de esta peste. Sin embargo, superada la modernidad, fue en los Estados con menor grado de desarrollo y con condiciones de insalubridad notorias, como los países de América Latina, que la viruela mató y deformó a miles de personas, dejando en quienes lograron sobrevivir penosas secuelas arraigadas en el miedo.

La fiebre, los dolores, la postración y la inmovilidad eran los primeros síntomas presentados por las personas contagiadas; a estos malestares le seguía la aparición en todo el cuerpo de manchas rojas sobre las que se formaban bolsas de materia infectada, la constante picazón que éstas producían hacían que el doliente se rascara y con ello dispersara la infección. Al reventarse las bolsas de materia, por proceso natural o acelerado por el enfermo, el liquido con aspecto y olor nauseabundo salía, provocaba costras que con el tiempo cicatrizaban y dejaban huellas perdurables en quienes la padecieron. Entre las complicaciones más frecuentes de la viruela estaba la ceguera, resultado de la lesión en las córneas y el estallido de los globos oculares, al igual que las afecciones respiratorias y daños del sistema nervioso y renal, la mayoría de las veces irreversibles. En las víctimas letales, la viruela condujo lentamente a una muerte que muchos llamaron pegajosa o apelmazada.

Si se tiene en cuenta que la viruela era contagiosa desde que el enfermo presentaba los primeros indicios de la sintomatología $y$, al parecer los objetos que entraban en contacto con él eran igualmente agentes trasmisores; el desconocimiento parcial del origen de la enfermedad -de su etiología- y la dificultad para contrarrestarla desde las prácticas médicas, conllevaron a las autoridades, antes y después del periodo colonial, a generar una serie de políticas sanitarias y asistencialistas cada vez que la amenaza de la enfermedad se hacía latente en los territorios que ahora forman parte del Estado colombiano.

Si bien es cierto, el descubrimiento de la vacuna en 1798 por el médico inglés Edward Jenner fue una solución trascendental para menguar los alcances y posterior erradicación de la viruela en todo el mundo, en la Colombia del siglo XIX difícilmente se obtuvo y masificó la vacuna, fueron varias décadas las que se debieron esperar para el perfeccionamiento de la misma y, por ende, para su desaparición definitiva. Sólo a partir de los años setenta del siglo XX esta enfermedad dejó de constituirse en un problema para la sociedad colombiana.

Desde el colapso del periodo prehispáni$\mathrm{co}$, las sociedades latinoamericanas que terminaron configurándose como Estados a través de diferentes procesos históricos, estuvieron marcadas y asechadas por la viruela. Ésta y otras epidemias diezmaban drásticamente la población y fue así como varios cronistas e historiadores dieron cuenta de sus consecuencias desde su aparición hasta su eliminación en estos territorios, ante todo cuando superaba los umbrales epidemiológicos. No obstante, para el caso colombiano son pocos los trabajos que desde la historia se han realizado para comprender de manera más compleja y en diferentes periodos, la concepción y el impacto de la enfermedad, así como las medidas médicas, sanitarias y asistencialistas implementadas.

Entre estos trabajos cabe mencionar Las epidemias de viruela de 1782 y 1802 en el Nuevo Reino de Granada de Renán Silva, y Enfermedad y Sociedad en la crisis colonial del Antiguo Régimen de Marcelo Frías Núñez. Investigaciones 
que buscaron conocer los alcances de la enfermedad y las medidas tomadas para su contención a través del estudio de dos fuertes brotes epidémicos que se presentaron en el periodo colonial en 1782 y 1802. Sin embargo, la inexistencia de trabajos historiográficos sobre la viruela en otros periodos y espacios, conllevó a la realización de un trabajo de investigación histórica que buscó comprender la política de salubridad pública orientada a prevenir y controlar la viruela en el Estado Soberano de Santander entre 1857 y 1886, mediante el análisis de la reglamentación dictada por el Gobierno Central y el del Estado.

Es recurrente aclarar que el trabajo no es un estudio histórico de la enfermedad en sí, ni del impacto de sus consecuencias en las representaciones sociales o en el desarrollo material de las poblaciones. No se pretendió realizar un estudio detallado respecto al número de víctimas, ni la caracterización de ellas o de los lugares en donde la población fue más susceptible al contagio. Si bien, las políticas de Estado son el reflejo del ideal o del deber ser, distantes algunas veces del ser que concentra la materialización de las mismas; el estudio de las medidas del Gobierno para prevenir el contagio de la viruela y controlar sus nefastas consecuencias, permitió reconocer la actitud de los diferentes actores políticos, médicos y religiosos, al igual que la resistencia a los mismos por parte de los diferentes sectores sociales.

Los resultados finales de esta investigación se muestran de manera general en el presente artículo, identifica la reacción del Gobierno de la Unión y del Gobierno del Estado de Santander frente al peligro que representaban los brotes epidémicos de viruela durante el periodo federal de los Estados Soberanos, época donde el radicalismo liberal manifestó su intención de contribuir a garantizar a la población mejores condiciones de salud para facilitar el desarrollo económico del país, al dispo- nerse de una mano de obra en adecuado estado físico. Con este trabajo se buscó contribuir a la consolidación de los estudios históricos sobre salud pública, además, es significativo para la historiografía colombiana reconocer las repuestas que los diferentes organismos y la población en general dieron a una enfermedad que por la magnitud de sus consecuencias generó gran estupor y pánico.

\section{Metodología}

Para efectuar el estudio sobre las epidemias de viruela en el Estado Soberano de Santander se acudió al método heurístico y hermenéutico, propios de la investigación histórica. El primero para localizar, organizar y establecer la calidad y el aporte de las fuentes documentales que sustentan la investigación; y el segundo para hacer crítica y contrastación de la información recolectada, con el fin de garantizar un acercamiento objetivo al hecho histórico abordado. El trabajo se apoyó principalmente en fuentes primarias, por relacionarse estrechamente en el tiempo y en el espacio con el acontecimiento estudiado y porque las fuentes secundarias eran escasas. La información en su totalidad se obtuvo del Archivo General del Departamento de Santander, del Archivo Histórico Regional (CDHIR), de la Biblioteca Nacional y de la Biblioteca Luis Ángel Arango. Una vez la información fue recolectada, clasificada y sintetizada, se contrastaron las diferentes fuentes documentales para validar su contenido y culminar el proceso analítico y crítico. La organización de toda la información y la redacción del texto final, al igual que de este artículo, se presentó de manera cronológica y narrativa.

\section{La viruela}

La viruela es una enfermedad aguda, sistémica, infectocontagiosa, epidémica, de etiología viral, producida por el virus Variola, cuyo reservorio es sólo el hombre. La 
viruela es contagiosa, pero se propaga con menor facilidad que otras enfermedades, como la gripe o el sarampión. Si bien, es necesario un contacto prolongado para que la enfermedad se propague de una persona a otra, también puede propagarse a través del contacto directo con fluidos corporales, enseres y vestimentas, o en menor medida por el aire contaminado en espacios cerrados. Sobre la existencia de viruela en América, la historiografía ha demostrado que arribó junto con los nuevos habitantes en los inicios del siglo XVI.

Por el recelo y desprecio hacia los afrodescendientes se atribuyó su penetración a los esclavos provenientes de Etiopía. Sin embargo, para 1840 en Nueva Granada, persistía la creencia colonial que la viruela fue importada en los cobertores de lana que sirvieron de abrigo a los virulentos en el continente europeo [1]. Sin importar sí fueron los africanos o los europeos quienes trajeron la viruela a América, es claro que el no desarrollo de alguna inmunidad hizo más vulnerable a los nativos; el incumplimiento de las medidas sanitarias y la falta de medicamentos para su prevención y tratamiento fueron aspectos que facilitaron su rápida propagación y nefastas consecuencias, ya que causaba la muerte al $30 \%$ de las personas que la padecían, llegó a ser considerada una de las principales causas de despoblación [2].

Al territorio que en la actualidad comprende Colombia la viruela, al igual que todas las enfermedades contagiosas se propagó, en especial, por las rutas comerciales, y culminó en Santafé. Unas epidemias iniciaban en la costa norte, Cartagena, Santa Marta o Riohacha y pasaban por Mompox y Honda; otras provenían del sur, de Popayán se dirigían a Cali, Buga e Ibagué; y otras más iniciaban en Cúcuta dirigiéndose a Santafé a través de Ocaña y Tunja. Sin embargo, la viruela llegó a otros lugares mediante enfermos convertidos en agentes patógenos, especialmente en épocas de guerra.
La viruela, al igual que la lepra, por ser una enfermedad cuyas causas en un comienzo fueron desconocidas en términos de una patología médica, su contagio fue explicado por un conjunto de creencias religiosas. Los brotes epidémicos fueron atribuidos a los pecados de la población, siendo su contagio o posesión concebidos como un castigo divino. Asimismo, el haber delegado desde el inicio del periodo colonial a las comunidades religiosas la asistencia médica y social de los enfermos, vagabundos y desprotegidos, orientó la contención de la enfermedad a la intercesión de Dios; de ahí, que los clérigos encabezaron plegarias incesantes en busca de la condonación de los pecados de la población para el cese de la epidemia. No obstante, desde la epidemia de 1782 la causa de la viruela dejó de relacionarse plenamente con creencias cristianas, pasó a atribuirse a la insalubridad del individuo y su contexto, resultado de la pobreza e incivilidad.

La concepción miasmática se empleó para explicar la aparición y vertiginosa divulgación de la viruela.

“Los miasmas eran vapores deletéreos o efluidos generados en aguas estancadas, excrementos, materias en descomposición o emanaciones del subsuelo que, supuestamente, entraban en acción por la humedad, la suciedad, los vientos y los cambios atmosféricos" [3].

Los pobres por su modo de vida y sus costumbres fueron considerados el principio de la cadena etiológica.

Si bien, la viruela afectó a individuos de diversa condición socio-económica, racial y cultural, evidentemente tuvo una inclinación hacia las personas de capas sociales inferiores, por vivir la mayoría en condiciones de hacinamiento y con notables carencias materiales, hecho que incrementó el estigma hacia la enfermedad y sus convalecientes pero, a su vez, direccionó la atención 
de las autoridades a la búsqueda de soluciones para dichos problemas.

Es así, como junto a las arraigadas creencias religiosas y populares sobre el origen y el tratamiento para contener la viruela, las autoridades buscaron incorporar en la población hábitos sanitarios que higienizaran los espacios y utensilios contaminados, puesto que ellos facilitaban la propagación de la enfermedad; medidas sanitarias que pronto generaron consecuencias significativas $^{[4]}$. No obstante, la insuficiencia de tratamientos y asistencia médica especializada, medidas realmente eficaces, se suscitaron brotes epidémicos de viruela durante el siglo XIX, y en menor grado en el siglo XX.

\section{Las políticas del gobierno para contener las epidemias de viruela en el Estado Soberano de Santander}

Durante las primeras décadas del siglo XIX, los procesos de conformación de la Nueva Granada en una República libre y autosuficiente, trajo consigo una profunda crisis política, económica y social, la cual buscó solucionarse en 1857 con la división político administrativa del país en Estados Confederados, dirigidos por liberales Federalistas, quienes con espíritu reformista acogían con mayor vigor la idea de progreso y apertura hacia las fuerzas modernizadoras, que concebían este sistema de poder como la mejor forma de alejar al país del subdesarrollo e incivilidad en que se encontraba, a la par que percibían el bienestar social y cultural de la población como un requisito para materializar las ideas de progreso y como resultado del mismo.

El Estado de Santander se instituyó bajo la ley del 13 de mayo de 1857, a través del Senado y la Cámara de Representantes, quienes decretaron que las provincias de Pamplona, Socorro y Ocaña formaran un Estado federal; tiempo después a este territorio se anexaron otras provincias. Los liberales consideraban que mientras el país continuara constituido por individuos pobres, enfermos e insalubres las condiciones de atraso difícilmente podrían ser superadas; por lo cual se debía sanar, instruir y ocupar productivamente a toda la población en los ramos de la economía que permitieran la consolidación de los proyectos políticos y culturales del Estado y la Nación. Sin embargo, cuando se revisa la documentación oficial y como se demostró con la investigación realizada, es evidente que la salubridad pública fue un aspecto relacionado con la beneficencia y la asistencia a los pobres, enfermos, desamparados y moribundos. La mayor intervención de las autoridades gubernamentales en procura de un adecuado estado de la salud de la población tan sólo se dio cuando las enfermedades endémicas o epidémicas tendieron a desestabilizar la dinámica socioeconómica del Estado, era en esos momentos cuando las autoridades empezaban, con mayor compromiso, a decretar medidas orientadas a garantizar un mejor estado de salud de los habitantes y a disponer de fondos para la materialización de las mismas.

La salubridad pública dentro de la nueva conformación político administrativa del país, asumió una doble vía de realización:

"una de carácter central e institucional dependiente de las disposiciones nacionales y estatales, como de las ejecuciones político-administrativas del gobierno local o provincial a través de sus instituciones, y otra descentralizada y asociativa que siendo independiente del gobierno provincial o nacional y sus instituciones, era liderada y financiada a través de las organizaciones de los particulares en asocio a las autoridades locales, aunque sin estar condicionados en su legalidad a las disposiciones estatales o nacionales" [5].

La insuficiencia de fondos para la materialización de los postulados liberales que ansiaban un país próspero y civilizado, estableció como política de Estado evitar el gasto de las rentas para suplir las necesidades provinciales y locales. En con- 
secuencia, se confió a particulares o a las organizaciones cívicas o de beneficencia reglamentadas por los cabildos, la responsabilidad de garantizar al desvalido un adecuado estado de salud, sin la colaboración de los funcionarios, instituciones o fondos públicos, tan sólo se podía contar con ellos cuando la gravedad de la dolencia tendía a expandirse y afectaba a un mayor número de personas. De lo contrario eran los individuos pudientes quienes debían, como acto humanitario para con el necesitado, ayudarles a gozar de una mejor salud. El destinar parte de sus riquezas en auxiliar a infectados o agonizantes reflejaba el cumplimiento de sus compromisos cristianos y ciudadanos, garantizaba reconocimiento y agradecimiento, a la par que reducía la posibilidad de enfermarse al disminuir los agentes contaminantes. De ahí que los administradores del Estado de Santander promovieron entre sus habitantes, en especial entre la población pudiente, sentimientos patrióticos y caritativos; la salubridad de la población fue concebida como una preocupación general [6].

A través del proceso investigativo se identificó la presencia en el Estado de Santander de cuatro bastos brotes de viruela, en 1857, 1871 y 1881; además se reconoció que las políticas decretadas por las autoridades para mitigar sus efectos se direccionaron en cinco ejes, de esa manera se abordaron en el trabajo final y se presentan en este artículo. Primero, frente a la capacidad de la viruela de extenderse vertiginosamente una vez se presentaba, así fuera en casos aislados, la conformación de Juntas de Sanidad fue la medida adoptada inicialmente, puesto que eran ellas las encargadas de coordinar y ejecutar las políticas estatales. Segundo, el desconocimiento de las causas que generaban la viruela, priorizó la higienización de los poblados, decretándose medidas y sanciones que impulsaban su cumplimiento. Tercero, la necesidad de prevenir la expansión de la epidemia y el temor que provocaba el observar el desarrollo de la enfermedad en quien la padecía, conllevó a la adecuación de lugares aislados de las poblaciones, para erigir hospitales provisionales y concentrar allí a la población enferma o sospechosa de serlo. Cuarto, la intención de inmunizar al mayor número de personas posible y la efectividad de los métodos de inoculación, vacunación ó inoculación de la vacuna, hizo que la prevención de la viruela -o al menos el propósito- se buscara en alguna de estas prácticas, a las que se les otorgó relevancia y prioridad. Y quinto, si bien los métodos curativos fueron escasos y poco acreditados, desde la oficialidad se recomendaron remedios para evitar la complicación de la enfermedad, la cual podía terminar por lisiar o llevar al fenecimiento de quien la padecía.

\section{1: Juntas de Sanidad}

Durante todos los brotes epidémicos que se presentaron en Santander, la primera disposición decretada fue la conformación de Juntas de Sanidad para coordinar y ejecutar las disposiciones médicas y sanitarias que permitieran contener los focos endémicos o brotes epidémicos, al igual que suministrar los auxilios a las personas contagiadas. Para una mayor cobertura y un mejor servicio, se instauró una Junta principal en la capital de Estado y una en cada uno de los Departamentos, por lo menos en los más afectados. Éstas fueron integradas por individuos, que a criterio del ejecutivo eran los más idóneos para desempeñar las funciones que se le encomendaban, éstos podían ser empleados públicos o individuos particulares. Con la finalidad de prevenir todo aquello que pusiera en riesgo la salubridad pública se les concedió a las Juntas de Sanidad la facultad para dictar e institucionalizar medidas de policía, siempre que no contrariaran las leyes [7]. Sobre éstas recayó la responsabilidad de detener los brotes de viruela, con su conformación el Estado delegó gran parte de sus responsabilidades. 


\section{2: Saneamiento}

Habida cuenta que los ambientes contaminados hacían a las personas más proclives al contagio, se buscó incesantemente el saneamiento y purificación de los espacios; la adecuación física y sanitaria de los poblados se convirtió en un objetivo principal para evitar la aparición y proliferación de la viruela y de otras enfermedades difíciles de contener. Se destinaron partidas del presupuesto público y se legisló específicamente para empedrar las calles, construir canales o alcantarillas, sustituir los suelos enladrillados de las casas por suelos con maderamen, construir letrinas y arborizar las vías; al igual que se promovió el uso de baños y lavaderos públicos para la salud corporal, y la limpieza de las calles y las vías públicas [5].

La mayoría de las medidas de higienización fueron concentradas en el Código de Policía, pero los alcances de algunos brotes epidémicos conllevaron a adoptar de imprevisto nuevas medidas o reforzar las existentes. Sustentada en razones benéficas, la exclusión de los enfermos y de los cadáveres, también fue adoptada por las autoridades del Estado de Santander, quienes se opusieron a que los individuos exentos de dolencias y contagios compartieran los espacios públicos con los enfermos, vagabundos y difuntos, puesto que la posibilidad de contagio era evidente.

Si bien, a inicios del siglo XIX se dispusieron terrenos comunes de fondos presupuestales y los planos arquitectónicos necesarios para el levantamiento de cementerios rurales, sólo el temor a contraer la lepra, enfermedad que discapacitada y descomponía el cuerpo de los dolientes, o la viruela, enfermedad que rápidamente podía acabar con la vida de quien la padecía, fueron aspectos que facilitaron la adopción de las prácticas fúnebres en lugares distantes a los templos religiosos bajo las recomendaciones dadas por las autoridades médico sanitarias e impul- sadas y controladas por las autoridades gubernamentales.

A partir de la segunda mitad del siglo XIX, más allá de las disputas entre el clero y el régimen liberal por el control de los camposantos, es importante resaltar el interés de los funcionarios gubernamentales por reglamentar y materializar las políticas de salubridad pública que por varios siglos fueron delegadas al ámbito privado, las cuales culminaron en el acatamiento por parte de la población de la normatividad sanitaria para la ejecución de rituales fúnebres.

\section{3: Hospitales de Virulentos}

El temor a lo desconocido, a lo desagradable, a lo incontrolable y al contagio de esto, conllevó a las autoridades gubernamentales a buscar el aislamiento del agente patógeno o de los individuos que causaban estupor en la población por padecer alguna enfermedad o desviación en su comportamiento. En consecuencia, cada vez que la viruela se presentaba la instauración de hospitales provisionales fue una medida asistencial y sanitaria contemplada por las autoridades. Si bien, se deseó cambiar la finalidad de los hospitales de virulentos para convertirlos en centros de atención médica, en donde los enfermos obtuvieran curación rápida y sin mayores consecuencias; la escasez de fondos y de personal especializado, la renuencia del enfermo a ser señalado y alejado de su entorno familiar, así como la insistencia de los funcionarios políticos, médicos y hasta religiosos, por evitar el contacto de los contagiados con la población exenta, obstaculizaron la efectividad y eficacia de estos centros hospitalarios.

\section{4: Inoculación, vacunación o inoculación de la vacuna}

La inoculación fue una práctica originaria de Asia y llegó a Europa a comienzos del siglo XVIII, época en la que las epidemias de viruela generaban un alto índice de 
mortalidad, por lo que desde entonces se realizaron como uno de los pocos y más efectivos métodos de prevención contra esta enfermedad, pese a los riesgos que podía provocar en algunas personas cuando, contrario a lo esperado, el mal se desataba con violencia.

La técnica de inoculación consistía en trasplantar pus de las pústulas de un enfermo de viruela a una incisión o punción en la piel de una persona sana. De ella resultaba una infección generalmente benigna, cuyas posibilidades de supervivencia eran mucho mayores que en el caso de infección por contagio natural [2]. Otra forma de inocular fue mediante el "método griego", que consistía realizar cuatro punturas cruciformes con linfa variólica en la frente, el mentón y los pómulos.

A la Nueva Granada esta técnica llegó a finales del siglo XVII promovida por José Celestino Mutis, quien estudiaba y difundía el mecanismo para prevenir y menguar los efectos de los brotes epidémicos de viruela que se daban en varias regiones del Virreinato, y quien publicó un folleto con instrucciones para efectuar dicho procedimiento ${ }^{[8]}$. Si bien, la variolación debía ser realizada por médicos, la carencia de ellos obligó a religiosos, curanderos, parteras, boticarios y barberos a efectuar estas incisiones.

A pesar de la efectividad de la inoculación en los países en que se implementaba, en Colombia existió gran recelo y desconfianza para su realización. Al comienzo tan sólo fue acogida por las principales familias, quienes también llevaron a sus criados a inocularse; las personas de escasos recursos, incluidos los indios se resistieron a ella. Fue el tiempo, la obligatoriedad y la comparación de sus efectos positivos ante los negativos, los que permitieron la aceptación y la extensión de esta práctica.

Lo anterior y la oposición de algunos médicos y funcionarios públicos para quienes la variolación no lograba convencerlos por los peligros que podía generar, obstaculizó la masificación de dicha práctica. Aún así, fueron miles las personas inoculadas, se logró evitar que la enfermedad se propagara con la misma intensidad que lo hizo en los tiempos en que no se realizaba; se disminuyó en un alto porcentaje las consecuencias fatales de la viruela hasta la aparición de la vacuna.

La verdadera prevención contra la viruela pareció encontrarse en 1798 en Inglaterra. Dos años atrás, en la provincia de Gloucestershire, los rumores existentes entre la población acerca del no contagio de viruela en los encargados de ordeñar las vacas que fueron contagiados de una erupción que aparecía en las ubres de los animales conocida como cow pox o viruela de las vacas, llevó al médico Edward Jenner a infiltrar en el cuerpo humano la linfa de una pústula para comprobar que era un método inocuo que evitaba el contagio de la viruela humana [8]. Al demostrarse su efectividad se extendió su aplicación y llegó a las colonias españolas en América a comienzos del siglo XIX.

Sin embargo, en estos lugares de inmediato se dieron los mismos inconvenientes que se presentaron en Europa. La dificultad para encontrar la sustancia en las vacas y de importarlo por las alteraciones o daños que podía sufrir el fluido al ser transportado de tan vastas distancias y a través de diversos climas, aumentó la preferencia de la práctica de la inoculación.

No obstante, en el tiempo y el espacio estudiado la dificultad para contar con suficiente cantidad del virus vacuno generado por los bovinos, llevó a que éste fuera extraído de las personas vacunadas e inoculado en otros individuos, práctica denominada inoculación de la vacuna. Al igual que con la inoculación, las personas encargadas de inocular la vacuna creían que la sustancia más apta para ser nuevamente infiltrada a otros individuos era la desarrollada por la población infante que se encontraba en adecuado estado físico. 
Para debilitar la resistencia de la población a recibir los beneficios del virus vacuno y a prestarse como vehículos reproductores, las autoridades del Estado Soberano de Santander encargadas de mitigar la viruela y sus efectos, hicieron constantes llamamientos a médicos, religiosos, comerciantes, hacendados y educadores para que convencieran a todos los demás habitantes del Estado sobre la importancia de contribuir a la prevención y si era posible a la erradicación plena de la viruela del contexto nacional. Ostentadas las ventajas de la vacuna $y$, contrario a los rumores de los peligros y dolores que padecían quienes se inmunizaban, se dio inicio a la campaña para obtener el pus vacuno y hacerlo extensivo al mayor número de individuos posibles.

Asimismo, desde la capital de la Unión, la naciente comunidad médica, incapaz de dar solución a la enfermedad con conocimientos propios, promovió artículos para dar a conocer investigaciones de las Sociedades Científicas europeas sobre la clasificación y tratamiento de la viruela, a la par que buscó desmentir las afirmaciones que hacían los detractores de la vacuna, puesto que estos estudios aseveraban que la verdadera vacuna aplicada según las pautas establecidas preservaban a la sociedad para siempre de la viruela.

No obstante, la dificultad de contar con las suficientes dosis de pus vacuno y con la calidad requerida para inmunizar efectivamente a un alto porcentaje de individuos, la inexperiencia de varios vacunadores, la resistencia de algunas personas a vacunarse por el temor al dolor, a la muerte o a contraer otras enfermedades relacionadas equívocamente con la vacuna y la carencia de recursos económicos para emprender masivamente jornadas de vacunación, fueron los mayores y constantes impedimentos con los que debieron enfrentarse los Gobernantes del Estado Soberano de Santander y los organismos constituidos por médicos, religiosos, sacerdotes y personalidades prestantes de la región, quienes por beneficencia, por miedo a que el contagio los alcanzara o por evitar el del desarrollo del Estado, unieron intereses y esfuerzos por derrotar la viruela con el arma más efectiva, la vacuna.

\section{5: Difusión de recetas caseras}

Por último, como complemento de las medidas anteriormente expuestas y por no haberse logrado medicalizar la viruela, desde las publicaciones oficiales se difundieron recetas caseras, con las cuales reconocidas personalidades aseguraban haberse curado o lograr sanar a otros [9]. Eduardo Hino, quien se mentaba como hombre prestante y público del Estado, apostaba su reputación a prevenir y curar la viruela en tres días con Crémor Tartárico. Una onza de esta sustancia se disolvía en media botella con agua hirviendo, una vez se enfriara se debía tomar en cortos intervalos. El mismo Hino aseguraba haber sanado a centenares de enfermos con dicho remedio sin causarles ceguera y evitándoles una curación larga y fastidiosa o en el peor de los casos, su fenecimiento. Convencido de su efectividad, Eduardo Hino enviaba una copia de la receta al diario "El Mercurio" de Liverpool. Esta receta fue tan sólo un ejemplo de las muchas que las autoridades del Estado difundían con el ánimo de contener la propagación de la viruela; a pesar la poca efectividad de estos tratamientos, para el gobierno cualquier alternativa era válida.

\section{Conclusiones}

S la bien, la escasez de fuentes documentales no permiten plenamente constatar el cumplimiento y la efectividad del trabajo realizado por las diferentes Juntas de Sanidad en el Estado de Santander para contener la propagación de la viruela, se puede plantear que la conformación de las Juntas de Sanidad y la promoción de la vacuna fueron, en especial, medidas de 
contingencia cuando existió el rumor o la aparición de casos concretos de viruela dentro del Estado o en los Estados vecinos, ya que al parecer una vez pasaba la amenaza de la enfermedad, en el Estado se disolvían las Juntas y desaparecía de la documentación oficial las políticas que prevenían la propagación de la epidemia. Aun así y pese a los inconvenientes que pudieron presentarse al aplicar las medidas existentes para disminuir el contagio y sus efectos en la población, los santandereanos no padecieron las inclemencias de la enfermedad en la misma magnitud que los residentes de otros Estados.

Si bien, en esta investigación la epidemia y sus consecuencias en sí mismas no se cuantificaron, los informes del poder ejecutivo del Estado al Gobierno Central, reflejaron que contrario a los presentados por las autoridades de otros Estados, en el de Santander cuando la enfermedad merodeaba y amenazaba con acentuarse, la movilización de los diferentes organismos por proteger a las personas en las zonas afectadas, generó que la viruela no se expandiera por todo el territorio $y$, donde se manifestara, cesara rápido. Es decir, las Juntas de Sanidad, la higienización de los poblados y de las personas, la exclusión de los virulentos en los hospitales, la promoción paradójica de tratamientos homeopáticos y la propagación de la vacuna como el método con mayor efectividad en la prevención de la enfermedad, fueron los armas del Estado Soberano de Santander para ganarle la batalla a la viruela, victoria que no logró producirse pero las víctimas de la lucha tendieron a disminuir.

Por otra parte, con la investigación se pudo concluir que en este contexto la noción de política sanitaria tuvo una doble significación originada en la lógica del liberalismo económico. El Estado estuvo obligado a promover la salud de los individuos para garantizar la productividad y generación de riquezas, requisito cumplido de manera formal; pero por la escasez de sus recur- sos y priorización de otros intereses, con frecuencia debió limitar el gasto público y su accionar sanitario y preventivo. De esta manera, la política sanitaria del Estado fue inconsistente, no se cumplió en el plano material, se redujo al asistencialismo y control de las enfermedades que como las epidemias afectaron las dinámicas socioeconómicas. Es decir, la estrechez económica de los nacientes Estados, la prioridad de otras inversiones de carácter público y la inestabilidad de los gobiernos durante el siglo XIX relegaron los temas relacionados con la salud de la población; el problema de la salud se leyó en términos de asistencialismo donde el responsable no fue el Estado sino las comunidades religiosas y otras organizaciones de beneficencia. A pesar de esto, las políticas decretadas para contener las epidemias de viruela en el Estado Soberano de Santander tuvieron alto grado de efectividad.

\section{Referencias}

[1] PLAN PROFILÁCTICO Y CURATIVO DE LA VIRUELA. 1840. BIBLIOTECA NACIONAL. VFDU1-1590. P. 1.

[2] COOPER, Donald. Las epidemias en la Ciudad de México 1761- 1813. México: Instituto Mexicano del Seguro social, 1980. P. -113.

[3] RESTREPO, Estela. El cólera en Nueva Grana. En: Higienizar, medicar, gobernar: historia, medicina y sociedad en Colombia. Medellín: La Carreta, 2004. p. 52.

[4] SILVA, Renán. Las Epidemias de Viruela de 1782 y 1802 en la Nueva Granada. Cali: Centro Editorial de la Universidad del Valle, 1992. Pp. 84-85.

[5] PÉREZ PINZÓN, Luis Rubén. Regenerar la muerte: La política sanitaria en el Estado Soberano de Santander. Instituciones de beneficencia, organizaciones de caridad y establecimientos de salubridad (lazaretos, hospitales y cementerios) 1857 - 1886. Bucaramanga 2004. Trabajo de grado (Magíster en Historia). Universidad Industrial de Santander. Facultad de Ciencias humanas. Escuela de Historia. Pp. 6-7, 554-555.

[6] GACETA DE SANTANDER. SOCORRO, 12 de mayo de 1881. Año XXIII. p. 1493.

[7] CÓdIGO POLÍTICO Y MUNICIPAL, de Policía, Penal y Militar del Estado Soberano de Santander. Socorro: Imprenta Arenas y Cancino, 1866. p. 77.

[8] FRÍAS NÚÑEZ, Marcelo. Enfermedad y Sociedad en la Crisis Colonial del Antiguo Régimen. Madrid: Consejo Superior de Investigaciones Científicas 1992. Pp. 69- 89, 158.

[9] GACETA DE SANTANDER. SOCORRO, 12 de mayo de 1881. Año XXIII. p. 1493. 